\title{
COBERTURA NITROGENADA EM GIRASSOL SOB PLANTIO DIRETO NA PALHA: II - MORFOLOGIA DA PLANTA E PARTIÇÃO DE MASSA SECA ${ }^{1}$
}

\author{
BROADCASTING NITROGEN IN NO-TILLAGE OF SUNFLOWER: \\ II - PLANT MORPHOLOGY AND DRY MATTER PARTITION
}

\author{
Denise Heimbecker BRUGINSKI ${ }^{2}$ \\ Amir PISSAIA ${ }^{3}$
}

\begin{abstract}
RESUMO
O presente trabalho, conduzido no ano agrícola de 1998/99, teve como objetivo avaliar o efeito de diferentes doses de nitrogênio em cobertura no cultivo do girassol (Helianthus annuus L.), em sistema de plantio direto, sobre a morfologia da planta e partição de massa seca. O experimento foi conduzido na Fazenda Agripastos, em Palmeira, região dos Campos Gerais do Paraná, em um argissolo vermelho-amarelo, cultivado em sistema de plantio direto desde 1976. O delineamento experimental utilizado foi o de blocos ao acaso, com quatro repetições. Os tratamentos testados corresponderam às seguintes doses de nitrogênio: $0,25,50,75$, 100 e $125 \mathrm{~kg} \cdot \mathrm{ha}^{-1}$. Como fonte de $\mathrm{N}$ utilizou-se a uréia, que foi aplicada em cobertura, quando as plantas se encontravam no estádio $\mathrm{V}_{8}$. Foram amostradas cinco plantas por unidade experimental nos estádios $\mathrm{V}_{8}, \mathrm{~V}_{17}$ $R_{1}, R_{5,5}$ e $R_{7}$, para avaliação das variáveis: número total de folhas, altura da planta, diâmetro do caule, área foliar, índice de área foliar, diâmetro do capítulo e partição de massa seca. Aadubação nitrogenada em cobertura, nas condições deste experimento, não alterou a partição de massa seca e as características morfológicas do girassol.
\end{abstract}

Palavras-chave: sistema de produção, Helianthus annuus L., adubação nitrogenada.

\begin{abstract}
The present work, carried-out in the agricultural year of 1998/99, had as an objective to evaluate the effect of different levels of nitrogen in covering in the sunflower cultivation (Helianthus annuus L.) in notillage system about morphologic characteristics and dry matter partition. The experiment was driven at Fazenda Agripastos, in Palmeira, region of Campos Gerais, Paraná, in a red-yellow argissol, cultivated in no-tillage system since 1976. The experimental design used was the randomized blocks with four repetitions. The tested treatments were: doses of nitrogen $\left(0,25,50,75,100\right.$ and $\left.125 \mathrm{~kg} \cdot \mathrm{ha}^{-1}\right)$, in the urea form, applied in covering when the plants were met in the $\mathrm{V}_{8}$ stage. For the evaluations five plants were sampled in an experimental unit in $V_{8}, V_{17}, R_{1}, R_{5.5}$ and $R_{7}$ stages, to evaluated the variables: total number of leaves, height of the plant, diameter of the stem, area to foliate, foliate area index, diameter of the capitulum and matter partition drought. The nitrogen fertilization in covering, in the conditions of the experiment, didn't present any changing in the partition of dry matter and the morphologic characteristics of the sunflower.
\end{abstract}

Key-words: production system, Helianthus annuus L., nitrogen fertilization.

\footnotetext{
${ }^{1}$ Extraído da dissertação de mestrado do primeiro autor, apresentada ao Curso de Pós-graduação em Agronomia - Produção Vegetal, Universidade Federal do Paraná.

${ }^{2}$ Engenheira Agrônoma, CREA-PR 28300-D, M.Sc., aluna de doutorado do Curso de Pós-graduação em Agronomia - Produção Vegetal, UFPR, bolsista da CAPES. Rua dos Funcionários, 1540, Curitiba/PR, CEP 80035-050. denisehb@agrarias.ufpr.br

${ }^{3}$ Engenheiro Agrônomo, CREA-PR 3480-D, Dr., professor adjunto do Departamento de Fitotecnia e Fitossanitarismo, Setor de Ciências Agrárias, UFPR.
} 
BRUGINSK, D.H. e PISSAIA, A. Cobertura nitrogenada em girassol...

\section{INTRODUÇÃO}

O girassol é utilizado na alimentação humana e animal, mas também apresenta aptidão ornamental e propriedades medicinais. O grande atrativo da cultura é a possibilidade de produção de óleo de excelente qualidade, principalmente pela presença de significativa quantidade de ácido linoléico, essencial para o organismo humano. Entre os óleos vegetais, o de girassol é considerado como o de melhor qualidade nutricional e organoléptica.

Como opção na rotação de culturas, o girassol já foi estudado por vários autores em diferentes situações de clima, nível de adubação nitrogenada e sistema de cultivo $(9,12,22,24)$

O sistema de plantio direto proporciona uma série de alterações nas características físicas, químicas e biológicas do solo, modificando a necessidade de tratos culturais, quando comparado com o sistema convencional (17).

As doses de nitrogênio atualmente aplicadas em cobertura, no cultivo do girassol em sistema de plantio direto seguem a recomendação feita para plantio convencional, mas a possibilidade de redução das doses recomendadas pode reduzir o custo de produção. Castro et al (3) relataram o maior rendimento de girassol adubado com $90 \mathrm{~kg} \cdot \mathrm{ha}^{-1}$ de $\mathrm{N}$, enquanto que a dose considerada mais econômica foi de $17,5 \mathrm{~kg}$.ha ${ }^{1}$ de N.

A planta de girassol, quando submetida a diferentes doses e épocas de aplicação de nitrogênio em cobertura, apresenta alterações na produção de massa seca de folhas, hastes e capítulos. Além de alterações na área foliar, altura da planta, peso de aquênios, número de aquênio por capítulo e diâmetro do capítulo. A quantidade total de nitrogênio que pode ser absorvido por uma cultura de girassol influencia no valor máximo esperado para o índice de colheita (13, 14, 21, 25).

Com a finalidade de comprovação, formulouse a hipótese: se as características intrínsecas a um sistema de cultivo podem alterar a disponibilidade de nitrogênio para as plantas, então diferentes doses de nitrogênio aplicado neste sistema de cultivo, tem efeito sobre a morfologia da planta e a partição de massa seca.

O objetivo deste trabalho foi avaliar o efeito de diferentes doses de nitrogênio em cobertura no cultivo de girassol, em sistema de plantio direto, sobre a morfologia da planta e partição de massa seca.

\section{METODOLOGIA}

O experimento foi conduzido no ano agrícola de 1998/99, na Fazenda Agripastos, no município de Palmeira, região do Campos Gerais do Paraná, localizado entre as coordenadas de $25^{\circ} 21^{\prime}$ de latitude Sul e $49^{\circ} 56^{\prime}$ de longitude Oeste e altitude de $820 \mathrm{~m}$ (7). O solo foi caracterizado como argissolo vermeIho-amarelo, textura média, (5), com as seguintes características químicas (Tabela 1).

TABELA 1 - Caracterização química do solo da área experimental, Fazenda Agripastos, Palmeira, PR. $1998 .{ }^{1}$

\begin{tabular}{ccccccccc}
\hline $\begin{array}{c}\text { Profundidade } \\
(\mathrm{cm})\end{array}$ & $\begin{array}{c}\mathrm{pH} \\
\left(\mathrm{CaCl}_{2}\right)\end{array}$ & $\mathrm{Al}^{+3}$ & $\begin{array}{c}\mathrm{H}+\mathrm{Al} \\
\left(\mathrm{cmol}_{\mathrm{C}} \cdot \mathrm{dm}^{-3}\right)\end{array}$ & $\begin{array}{c}\mathrm{Ca}^{+2}+\mathrm{Mg}^{+2} \\
\mathrm{~K}^{+}\end{array}$ & $\begin{array}{c}\mathrm{P} \\
\left(\mathrm{mg}_{\mathrm{dm}}{ }^{-3}\right)\end{array}$ & $\begin{array}{c}\text { Matéria } \\
\text { orgânica } \\
\mathrm{g} \cdot \mathrm{dm}^{-3}\end{array}$ & $\begin{array}{c}\text { Saturação } \\
\text { por bases } \\
\%\end{array}$ \\
\hline $00-10$ & 4,4 & 0,3 & 5,8 & 4,2 & 0,2 & 6,0 & 33 & 43,1 \\
$10-20$ & 4,2 & 0,5 & 6,2 & 3,0 & 0,1 & 1,0 & 30 & 33,5 \\
$20-40$ & 4,0 & 0,7 & 6,7 & 2,8 & 0,1 & 1,0 & 21 & 30,3 \\
\hline
\end{tabular}

${ }^{1}$ Análises realizadas no Laboratório de Análises de Solos do Departamento de Solos da UFPR.

A área experimental teve a primeira interferência para cultivo agrícola em 1959. Em 1976, foi preparada para implantação do sistema de plantio direto e, a partir de 1981, foi adotado o plano de rotação de culturas que intercala nas safras de inverno cultivos de aveia-preta, cevada e trigo e, no verão, três anos consecutivos de cultivo da soja e um ano de cultivo do milho, neste experimento substituído pelo cultivo do girassol.

O delineamento experimental utilizado foi o de blocos ao acaso, com quatro repetições. Os tratamentos testados foram diferentes doses de nitrogênio: 0 , $25,50,75,100$ e $125 \mathrm{~kg}$ ha $^{-1}$, na forma de uréia, aplicadas em cobertura quando as plantas se encontravam no estádio $V_{8}$ (25 dias após a emergência).
Cada parcela foi formada por seis linhas com dez metros de comprimento, perfazendo área total de $54 \mathrm{~m}^{2}$, com média de 4,5 plantas. $\mathrm{m}^{-2}$. Em cada parcela, nos estádios $V_{8}, V_{17}, R_{1}, R_{5.5}$ e $R_{7}$ foram amostradas cinco plantas, cortadas rente ao solo, sempre na mesma linha eleita para as avaliações parciais, desprezando duas plantas entre cada grupo de cinco coletadas nos diferentes estádios de desenvolvimento.

O cultivo do girassol foi feito em sistema de semeadura direta sobre cobertura morta formada pelo cultivo da aveia-preta (Avena strigosa) dessecada (aplicação de 960 g.ha-1 de glyphosate, misturado com 0,5 L.ha- ${ }^{-1}$ de óleo mineral), uma semana antes da semeadura. 
Antes da semeadura da aveia-preta, foi feita a calagem superficial da área com aplicação de 1,5 t. ha $^{-1}$ de calcário dolomítico. A quantidade de massa seca produzida pela aveia-preta foi estimada em $3400 \mathrm{~kg} \cdot$ ha $^{-1}$. O fornecimento de nitrogênio foi de 54,4 kg.ha-1, considerando a média de $1,6 \%$ da palhada (15).

Foi utilizada a semeadora de grãos PAR 2800 , apropriada para o sistema de plantio direto, com quatro linhas de plantio distanciadas a $0,90 \mathrm{~m}$ e discos de semeadura recomendados para o cultivo do girassol, regulados para a distribuição de cinco sementes por metro de sulco, visando o estabelecimento de uma população de 50 mil plantas.ha-1 $^{-1}$ (4).

A semeadura foi realizada em setembro de 1998 utilizando-se o híbrido M 734 que é recomendado o estado do Paraná (6). Este híbrido apresenta ciclo tardio, maturação fisiológica aos 103 dias após a emergência e teor de óleo nos aquênios de aproximadamente $41 \%$ (16). A adubação de base foi feita com aplicação de $300 \mathrm{~kg}$.ha-1 da fórmula 00-26-26, seguindo a recomendação para semeadura convencional $(4,23)$ com base nos resultados da análise química do solo.

Dois dias antes da aplicação dos tratamentos, foi feito o sulcamento a $8 \mathrm{~cm}$ de profundidade utilizando uma adubadora adaptada para aplicação localizada de nitrogênio em cobertura no cultivo do milho em sistema de plantio direto, que funciona com um sistema de discos duplos, distanciados a $20 \mathrm{~cm}$ das linhas.

A quantidade de uréia correspondente aos respectivos tratamentos foi aplicada quando as plantas se encontravam no estádio de desenvolvimento $V_{8}$. Imediatamente após a distribuição o adubo foi incorporado, fechando-se os sulcos com auxílio de enxada.

Foi realizada a aplicação de 1,0 kg.ha-1 de boro, na forma de bórax (4). O bórax foi dissolvido em água a $70^{\circ} \mathrm{C}$ e aplicado com pulverizador costal manual quando as plantas se encontravam no estádio de desenvolvimento $\mathrm{V}_{9}$.

Para cada época de amostragem, foram coletadas cinco plantas de cada parcela experimental para avaliação das seguintes variáveis: a) número de folhas por planta; b) altura da planta, medida do nível do solo até a altura da inserção do capítulo; c) diâmetro do caule, à altura de $5 \mathrm{~cm}$ do solo; d) área foliar, medida por meio de aparelho integrador de área foliar "Automatic Area Meter" , modelo AAC 400; e) índice de área foliar, calculado por meio da fórmula: $\mathrm{IAF}=[(\mathrm{AF}) \mathrm{X}(\mathrm{P})] / 10000$, onde: $\mathrm{IAF}=$ índice de área foliar,
$\mathrm{AF}=$ área foliar $\left(\mathrm{cm}^{2}\right), \mathrm{P}=$ número de plantas. $\left.\mathrm{m}^{-2} ; \mathrm{f}\right)$ massa seca total, de caule, pecíolo, folha e capítulo, obtida após secagem em estufa com circulação forçada de ar e mantida à temperatura de $75^{\circ} \mathrm{C}$ até peso constante; e, g) diâmetro do capítulo, nos estádios $\mathrm{R}_{5.5}$ e $\mathrm{R}_{7}$

Os resultados foram submetidos à análise de variância utilizando o programa MSTATC. As variâncias dos tratamentos foram analisadas pelo teste de Bartlett. As variáveis cujas variâncias mostraram-se homogêneas tiveram as médias dos tratamentos testadas por meio do teste $\mathrm{F}$ a $5 \%$ de probabilidade (11).

\section{RESULTADOS E DISCUSSÃO}

Os tratamentos testados não influenciaram significativamente o número de folhas, altura da planta, diâmetro do caule, área foliar, índice de área foliar e diâmetro do capítulo, avaliados nos estádios $\mathrm{V}_{8}, \mathrm{~V}_{17}$, $\mathrm{R}_{1}, \mathrm{R}_{5.5}$, e $\mathrm{R}_{7}$ (Tabela 2).

Apesar de se considerar o girassol como uma espécie de grande plasticidade, adaptando-se a diversas situações de ambiente, o rendimento é altamente dependente de fatores do meio, como temperatura do ar, disponibilidade hídrica e de nutrientes (1). Halvorson et al. (9) estudaram durante 12 anos o rendimento de das culturas de trigo e girassol em rotação sob diferentes doses de nitrogênio e diferentes sistemas de cultivo e concluíram que a disponibilidade de água para as plantas durante os anos estudados foi determinante da resposta das plantas à quantidade de adubo aplicado e também ao manejo adotado. A precipitação pluviométrica desde a semeadura até a colheita do girassol no presente experimento foi de 664 $\mathrm{mm}$, o que pode ser considerado suficiente para o bom desenvolvimento do girassol que requer cerca de 500 a $700 \mathrm{~mm}$ de água durante seu ciclo (4). Neste caso, a falta de resposta da adubação nitrogenada não deve ser atribuída à distribuição das chuvas no período de crescimento da cultura.

Segundo Barni et al. (1) as plantas de girassol deficientes em minerais têm o rendimento reduzido devido, em grande parte, à redução da área foliar e, consequentemente, redução da taxa de fotossíntese. Os resultados obtidos estão em desacordo com Mundstock e Zagonel (13) que verificaram que o girassol responde à maior disponibilidade de nitrogênio no solo, aumentando a área foliar, conforme o genótipo. 
BRUGINSK, D.H. e PISSAIA, A. Cobertura nitrogenada em girassol...

TABELA 2 - Variáveis morfológicas das plantas de girassol, submetidas a diferentes doses de nitrogênio em cobertura, em sistema de plantio direto, Fazenda Agripastos, Palmeira, PR, 1998/991.

\begin{tabular}{|c|c|c|c|c|c|c|c|c|}
\hline \multirow{2}{*}{ Variáveis } & \multirow{2}{*}{ Estádios $^{2}$} & \multicolumn{6}{|c|}{ Dose de N (kg.ha $\left.{ }^{-1}\right)$} & \multirow{2}{*}{$\begin{array}{l}\text { Coeficiente de } \\
\quad \text { variação }\end{array}$} \\
\hline & & 0 & 25 & 50 & 75 & 100 & 125 & \\
\hline \multirow{5}{*}{$\begin{array}{c}\text { Número de } \\
\text { folhas }\end{array}$} & $\mathrm{V}_{8}$ & 8,2 & 8,2 & 8,5 & 8,6 & 8,4 & 8,5 & 5,68 \\
\hline & $V_{17}$ & 16,7 & 17,2 & 17,4 & 17,9 & 18,4 & 16,4 & 10,54 \\
\hline & $\mathrm{R}_{1}$ & 25,9 & 24,7 & 26,4 & 29,1 & 28,3 & 28,1 & 7,35 \\
\hline & $\mathrm{R}_{5.5}$ & 36,8 & 37,3 & 38,7 & 39,3 & 37,5 & 36,3 & 5,57 \\
\hline & $\mathrm{R}_{7}$ & 35,5 & 36,1 & 35,6 & 38,0 & 37,7 & 36,2 & 6,86 \\
\hline \multirow{5}{*}{$\begin{array}{c}\text { Altura da } \\
\text { planta } \\
(\mathrm{cm})\end{array}$} & $\mathrm{V}_{8}$ & 12,4 & 12,2 & 11,8 & 11,5 & 12,4 & 11,3 & 13,10 \\
\hline & $\mathrm{V}_{17}$ & 34,0 & 38,1 & 34,5 & 36,7 & 37,0 & 32,0 & 17,54 \\
\hline & $\mathrm{R}_{1}$ & 58,8 & 60,3 & 56,7 & 67,8 & 64,3 & 66,7 & 16,25 \\
\hline & $\mathrm{R}_{5.5}$ & 159,8 & 163,4 & 160,9 & 165,6 & 160,4 & 162,4 & 2,33 \\
\hline & $\mathrm{R}_{7}$ & 156,7 & 154,1 & 158,4 & 162,1 & 162,8 & 159,3 & 3,19 \\
\hline \multirow{5}{*}{$\begin{array}{c}\text { Diâmetro } \\
\text { do caule } \\
(\mathrm{mm})\end{array}$} & $V_{8}$ & 1,7 & 1,9 & 1,7 & 1,8 & 1,8 & 1,8 & 17,05 \\
\hline & $\mathrm{V}_{17}^{0}$ & 5,8 & 6,2 & 5,8 & 6,0 & 6,2 & 5,1 & 15,94 \\
\hline & $\mathrm{R}_{1}$ & 8,8 & 8,3 & 8,7 & 9,1 & 10,3 & 9,1 & 15,41 \\
\hline & $\mathrm{R}_{5.5}$ & 20,0 & 20,8 & 20,6 & 22,3 & 23,2 & 22,4 & 9,46 \\
\hline & $\mathrm{R}_{7}$ & 18,5 & 20,3 & 21,6 & 20,2 & 19,5 & 19,5 & 7,17 \\
\hline \multirow{5}{*}{$\begin{array}{l}\text { Área foliar } \\
\quad\left(\mathrm{cm}^{2}\right)\end{array}$} & $V_{8}$ & 822 & 881 & 862 & 954 & 929 & 882 & 36,90 \\
\hline & $V_{17}$ & 4122 & 4829 & 5065 & 5693 & 5285 & 4337 & 28,19 \\
\hline & $\mathrm{R}_{1}$ & 7864 & 8460 & 11206 & 12768 & 11918 & 13236 & 29,29 \\
\hline & $\mathrm{R}_{5.5}$ & 32932 & 32345 & 33079 & 35182 & 35771 & 33696 & 12,91 \\
\hline & $\mathrm{R}_{7}$ & 17348 & 20037 & 21822 & 20843 & 21501 & 20912 & 15,11 \\
\hline \multirow{5}{*}{$\begin{array}{l}\text { Índice de } \\
\text { área foliar }\end{array}$} & $\mathrm{V}_{8}$ & 0,36 & 0,40 & 0,39 & 0,42 & 0,44 & 0,37 & 34,46 \\
\hline & $V_{17}$ & 1,8 & 2,2 & 2,3 & 2,5 & 2,5 & 1,8 & 24,95 \\
\hline & $\mathrm{R}_{1}$ & 3,4 & 3,9 & 5,2 & 5,6 & 5,6 & 5,6 & 27,37 \\
\hline & $\mathrm{R}_{5.5}$ & 14,1 & 15,0 & 15,5 & 15,6 & 16,9 & 14,2 & 14,33 \\
\hline & $\mathrm{R}_{7}$ & 7,5 & 9,2 & 10,2 & 9,2 & 10,2 & 8,8 & 15,27 \\
\hline Diâmetro & $\mathrm{R}_{5.5}$ & 8,6 & 8,4 & 9,3 & 9,7 & 10,7 & 10,8 & 13,36 \\
\hline $\begin{array}{l}\text { do capítulo } \\
\text { (cm) }\end{array}$ & $\mathrm{R}_{7}$ & 16,3 & 17,5 & 18,4 & 17,1 & 16,8 & 16,2 & 6,83 \\
\hline
\end{tabular}

${ }^{1}$ Média de vinte plantas coletadas nos estádios $V_{8}, V_{17}, R_{1}, R_{5.5}$ e $R_{7}$,

2 Segundo a escala proposta por Schneiter e Miller (20).

Entretanto, o resultado encontrado confirma a conclusão de Barni et al. (1), de que níveis de adubação não evidenciam diferenças significativas no crescimento do girassol quando é alto o nível de fertilidade existente no solo.

O solo da área experimental vem sendo cultivado em sistema de plantio direto desde 1976 e, por este motivo, é possível que exista equilíbrio entre a mineralização e a imobilização de nitrogênio. As mudanças nas condições de temperatura, de umidade $e$ de porosidade do solo, sob sistema de plantio direto, resultam em uma tendência de elevação dos teores de matéria orgânica (10). O solo da área experimental com $33 \mathrm{~g} \cdot \mathrm{dm}^{-3}$ de matéria orgânica na camada de 0-10 cm (Tabela 1) confirma a tendência mencionada por Kochhann (10), já que esse teor pode ser considerado alto (23).

Segundo Sá et al (18), existe um aumento na concentração de carbono orgânico do solo sob sistema de plantio direto quando comparado com campo nativo e plantio convencional. Também Bayer e
Schneider (2) afirmaram que a taxa de acúmulo de matéria orgânica aumenta rapidamente nos primeiros anos de implantação do sistema de plantio direto e tende a atingir a estabilidade com o passar do tempo. Então, o desenvolvimento semelhante das plantas de girassol submetidas à diferentes doses de nitrogênio, observado neste experimento, deve-se a condição de solo presente na área experimental, proporcionada pelo sistema de cultivo empregado há vários.

Para Kochhann (10) a inclusão de espécies leguminosas no sistema de rotação de culturas pode ser usada como estratégia para diminuição da dependência de uso de fertilizantes nitrogenados. Estudando o efeito de resíduo de culturas sobre a resposta do milho a nitrogênio, Pöttker e Roman (15) concluíram que as leguminosas contribuíram com quantidades variáveis de nitrogênio para o milho, sendo que o tipo de cobertura vegetal precedente pode influenciar no desenvolvimento da cultura. Desta forma, a falta de resposta do girassol ao nitrogênio apli- 
cado, observado neste experimento, pode estar relacionada com a rotação de culturas empregada e também ao fornecimento de nitrogênio pela mineralização da matéria orgânica incrementada pela manutenção da palhada na superfície do solo.

O cultivo da área experimental, com a presença de leguminosa há mais de 20 anos no plano de rotação de culturas, e os resultados obtidos, sugerem que a quantidade mínima de nitrogênio necessá- ria para o desenvolvimento do girassol foi fornecida pelo solo.

Alguns autores atribuem as alterações no rendimento biológico de girassol à fonte orgânica ou mineral (8) e à quantidade de nitrogênio aplicada (14). Neste experimento, as diferentes doses de nitrogênio não alteraram a produção de massa seca de caule, pecíolo, folha e capítulo nos estádios $V_{8}, V_{17}, R_{1}, R_{5.5}$ e $R_{7}$ (Tabela 3).

TABELA 3 - Produção de massa seca de caule, pecíolo, folha, capítulo e total de plantas de girassol submetidas a diferentes doses de nitrogênio em cobertura, em sistema de plantio direto, Fazenda Agripastos, Palmeira, PR, 1998/991

\begin{tabular}{|c|c|c|c|c|c|c|c|c|}
\hline \multirow{2}{*}{ Variáveis } & \multirow{2}{*}{ Estádios $^{2}$} & \multicolumn{6}{|c|}{ Dose de N $\left(\mathrm{kg} \cdot \mathrm{ha}^{-1}\right)$} & \multirow{2}{*}{$\begin{array}{l}\text { Coeficiente } \\
\text { de variação }\end{array}$} \\
\hline & & 0 & 25 & 50 & 75 & 100 & 125 & \\
\hline \multirow{5}{*}{$\begin{array}{l}\text { Número de } \\
\text { folhas }\end{array}$} & $\mathrm{V}_{8}$ & 8,2 & 8,2 & 8,5 & 8,6 & 8,4 & 8,5 & 5,68 \\
\hline & $\mathrm{V}_{17}$ & 16,7 & 17,2 & 17,4 & 17,9 & 18,4 & 16,4 & 10,54 \\
\hline & $\mathrm{R}_{1}$ & 25,9 & 24,7 & 26,4 & 29,1 & 28,3 & 28,1 & 7,35 \\
\hline & $\mathrm{R}_{5.5}$ & 36,8 & 37,3 & 38,7 & 39,3 & 37,5 & 36,3 & 5,57 \\
\hline & $\mathrm{R}_{7}$ & 35,5 & 36,1 & 35,6 & 38,0 & 37,7 & 36,2 & 6,86 \\
\hline \multirow{5}{*}{$\begin{array}{c}\text { Altura da } \\
\text { planta } \\
(\mathrm{cm})\end{array}$} & $\mathrm{V}_{8}$ & 12,4 & 12,2 & 11,8 & 11,5 & 12,4 & 11,3 & 13,10 \\
\hline & $V_{17}$ & 34,0 & 38,1 & 34,5 & 36,7 & 37,0 & 32,0 & 17,54 \\
\hline & $\mathrm{R}_{1}$ & 58,8 & 60,3 & 56,7 & 67,8 & 64,3 & 66,7 & 16,25 \\
\hline & $\mathrm{R}_{5.5}$ & 159,8 & 163,4 & 160,9 & 165,6 & 160,4 & 162,4 & 2,33 \\
\hline & $\mathrm{R}_{7}$ & 156,7 & 154,1 & 158,4 & 162,1 & 162,8 & 159,3 & 3,19 \\
\hline \multirow{5}{*}{$\begin{array}{c}\text { Diâmetro } \\
\text { do caule } \\
(\mathrm{mm})\end{array}$} & $V_{8}$ & 1,7 & 1,9 & 1,7 & 1,8 & 1,8 & 1,8 & 17,05 \\
\hline & $V_{17}$ & 5,8 & 6,2 & 5,8 & 6,0 & 6,2 & 5,1 & 15,94 \\
\hline & $\mathrm{R}_{1}$ & 8,8 & 8,3 & 8,7 & 9,1 & 10,3 & 9,1 & 15,41 \\
\hline & $\mathrm{R}_{5.5}$ & 20,0 & 20,8 & 20,6 & 22,3 & 23,2 & 22,4 & 9,46 \\
\hline & $\mathrm{R}_{7}$ & 18,5 & 20,3 & 21,6 & 20,2 & 19,5 & 19,5 & 7,17 \\
\hline \multirow{5}{*}{$\begin{array}{l}\text { Área foliar } \\
\left(\mathrm{cm}^{2}\right)\end{array}$} & $V_{8}$ & 822 & 881 & 862 & 954 & 929 & 882 & 36,90 \\
\hline & $V_{17}$ & 4122 & 4829 & 5065 & 5693 & 5285 & 4337 & 28,19 \\
\hline & $\mathrm{R}_{1}$ & 7864 & 8460 & 11206 & 12768 & 11918 & 13236 & 29,29 \\
\hline & $\mathrm{R}_{5.5}$ & 32932 & 32345 & 33079 & 35182 & 35771 & 33696 & 12,91 \\
\hline & $\mathrm{R}_{7}$ & 17348 & 20037 & 21822 & 20843 & 21501 & 20912 & 15,11 \\
\hline \multirow{5}{*}{$\begin{array}{l}\text { Índice de } \\
\text { área foliar }\end{array}$} & $\mathrm{V}_{8}$ & 0,36 & 0,40 & 0,39 & 0,42 & 0,44 & 0,37 & 34,46 \\
\hline & $V_{17}$ & 1,8 & 2,2 & 2,3 & 2,5 & 2,5 & 1,8 & 24,95 \\
\hline & $\mathrm{R}_{1}$ & 3,4 & 3,9 & 5,2 & 5,6 & 5,6 & 5,6 & 27,37 \\
\hline & $\mathrm{R}_{5.5}$ & 14,1 & 15,0 & 15,5 & 15,6 & 16,9 & 14,2 & 14,33 \\
\hline & $\mathrm{R}_{7}$ & 7,5 & 9,2 & 10,2 & 9,2 & 10,2 & 8,8 & 15,27 \\
\hline Diâmetro & $\mathrm{R}_{5.5}$ & 8,6 & 8,4 & 9,3 & 9,7 & 10,7 & 10,8 & 13,36 \\
\hline $\begin{array}{l}\text { do capítulo } \\
\text { (cm) }\end{array}$ & $\mathrm{R}_{7}$ & 16,3 & 17,5 & 18,4 & 17,1 & 16,8 & 16,2 & 6,83 \\
\hline
\end{tabular}

${ }_{1}^{1}$ Média de vinte plantas coletadas nos estádios $V_{8}, V_{17}, R_{1}, R_{5.5}$ e $R_{7}$.

${ }^{2}$ Segundo a escala proposta por Schneiter e Miller (20).

Considerando a participação média percentual das partes sobre a massa seca total das plantas de girassol nas avaliações realizadas nos estádios $R_{5.5} e$ $\mathrm{R}_{7}$ obteve-se os dados apresentados na Figura 1.

A diferença percentual entre a massa seca do capítulo na fase de florescimento $\left(R_{5.5}=6 \%\right.$ da massa seca total) e na fase de colheita $\left(R_{7}=29 \%\right.$ de massa seca total) evidenciam uma grande transferência (partição) de massa seca em plantas de girassol, entre os estádios florescimento e maturação. Ao mesmo tempo, pode-se observar que a porcentagem de massa seca de folha, caule e pecíolo diminuem quando se considera o mesmo período.

A análise da produção e distribuição da massa seca na planta durante o enchimento de grãos é importante para compreensão das alterações verificadas no rendimento em função de uma determinada prática cultural (19). Neste caso, a prática da adubação nitrogenada não alterou significativamente a partição de massa seca das plantas de girassol. A falta de resposta pode ser associada ao histórico de uso da área experimental, ao plano de rotação de culturas e ao elevado teor de matéria orgânica disponível no solo (Tabela 1 ). 
BRUGINSK, D.H. e PISSAIA, A. Cobertura nitrogenada em girassol...

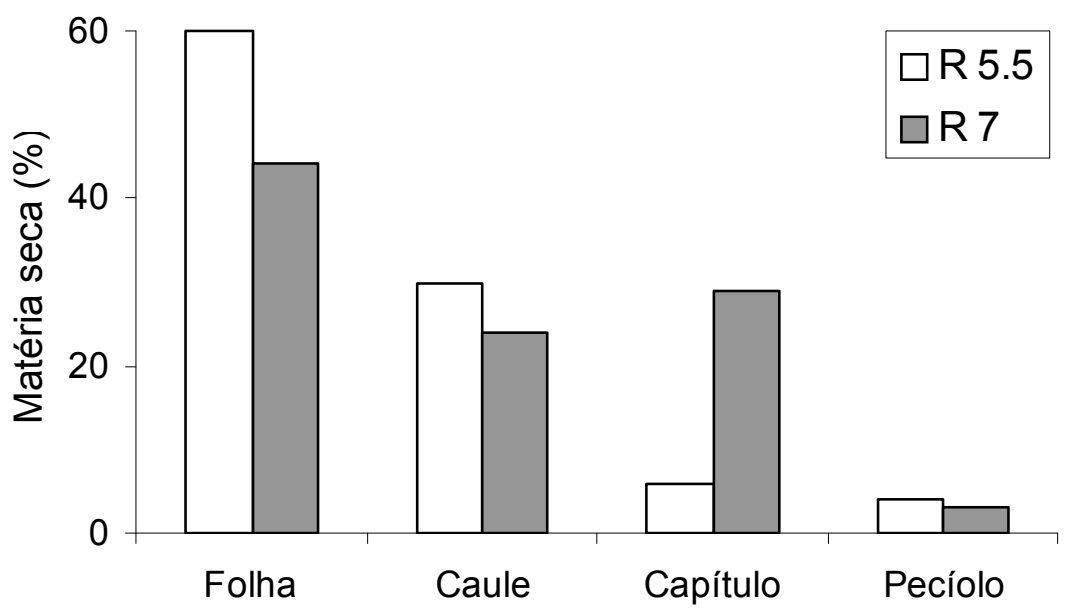

FIGURA 1 - Participação percentual de folha, caule, capítulo e pecíolo na massa seca total de plantas de girassol nos estádios $R_{5.5}$ e $R_{7}$, submetido a diferentes doses de nitrogênio em cobertura, em sistema de plantio direto, Fazenda Agripastos, Palmeira, PR, 1998/99.

A ausência de efeito significativo da adubação nitrogenada em cobertura sobre as variáveis morfológicas, partição de massa seca e rendimento médio obtido (2.053 kg.ha-1) são indicativos de que o sistema de plantio direto ( 25 anos) favoreceu o crescimento e desenvolvimento do girassol, mesmo na ausência de adubação nitrogenada.

Os resultados obtidos indicam a necessidade de se considerar o histórico de manejo da área de implantação do girassol para se definir a necessidade de recomendação de adubação nitrogenada, evitando em algumas situações o emprego desnecessário dos adubos.

\section{CONCLUSÕES}

1. A adubação nitrogenada em cobertura, nas condições deste experimento, não influencia as características morfológicas da planta e a partição de massa seca do girassol.

2. A quantidade de matéria orgânica do solo, o histórico de uso da área e o sistema de cultivo empregado são variáveis que devem ser consideradas para tomada de decisão quanto ao emprego dos adubos nitrogenados na cultura do girassol.

\section{REFERÊNCIAS BIBLIOGRÁFICAS}

1 BARNI, N. A.; BERLATO, M. A.; SANTOS, A. O.; SARTORI, G. Análise de crescimento do girassol em resposta a cultivares, níveis de adubação e épocas de semeadura. Pesquisa Agropecuária Guaúcha, Porto Alegre, v.1, n.2, p.167-184, 1995.

2 BAYER, C.; SCHNEIDER, N. G. Plantio direto e o aumento no conteúdo de matéria orgânica do solo em pequenas propriedades rurais no município de Teutônia. Ciência Rural, Santa Maria, v.29, n.1, p.155-166, 1999.

3 CASTRO, C. de; BALLA, A.; CASTIGLIONI, V. B. R.; SFREDO, G. J.; CASTRO, C. Doses e métodos de aplicação de nitrogênio em girassol. Scientia Agricola, Piracicaba, v.56, n.4, p.827-833, 1999.

4 CASTRO, C. de; CASTIGLIONI, V. B. R.; BALLA, A.; LEITE, R. M. V. B. de C.; KARAM, D.; MELLO, H. C.; GHEDES, L. C. A.; FARIAS, J. R. B. A Cultura do girassol. Londrina: EMBRAPA-CNPSo, 1997. 36p. (Circular Técnica, 13)

5 EMBRAPA/CNPS. Sistema Brasileiro de Classificação de Solos. Rio de Janeiro: EMBRAPA Solos, 1999. 412p.

6 EMBRAPA/CNPSo. Informes da avaliação de genótipos de girassol, 1996/97 e 1997. Londrina, 1997. 116p. (EMBRAPACNPSo. Documentos, 110)

7 FUNDAÇÃO INSTITUTO AGRONÔMICO DO PARANÁ. Cartas climáticas do Estado do Paraná. Londrina, 1984. 45p.

8 GORTTAPPEH, A. H.; GHALAVAND, A.; AHMADY, M. R.; MIRNIA, S. K. Effects of organic and integrated fertilizers on quantitative and qualitative traits of diffeent cultivars of sunflower (Helianthus annuus L.) in western Azarbayjan, Iran. Journal of Agricultural Sciences, v.6, n.2, p.85-104, 2000. 
9 HALVORSON, A. D.; BLACK, A. L.; KRUPINSKI, J. M.; MERRIL, S. D.; WIENHOLD, B. J.; TANAKA, D. L. Spring wheat response to tillage and nitrogen fertilization in rotation with sunflower and winter wheat. Agronomy Journal, Madison, v.92, n.1, p.136-144, 2000.

10 KOCHHANN, R. A. Alterações das características físicas, químicas e biológicas do solo sob sistema de plantio direto. In: CONFERÊNCIAANUAL DE PLANTIO DIRETO (1.:Passo Fundo: 1996) Resumos. Passo Fundo: Aldeia Norte Editora, 1996, p.17-25.

11 KOELHER, H. S. Estatística experimental. Curitiba: Universidade Federal do Paraná, 1998, 124p.

12 LOPEZ BELLIDO, L.; LOPEZ BELLIDO, R. J.; CASTILLO, J. E.; LOPEZ BELLIDO, F. J. Effects of tillage, crop rotation, and nitrogen fertilization on wheat under rainfed Mediterranean conditions. Agronomy Journal, Madison, v.92, n.6, p.1054-1063, 2000.

13 MUNDSTOCK, C. M.; ZAGONEL, J. Perfil de área foliar de duas cultivares de girassol sob doses e épocas de aplicação de nitrogênio em cobertura. Pesquisa Agropecuária Brasileira, Brasília, v.29, n.6, p.847-851, 1994.

14 POONIA, K. L. Effect of planting geometry, nitrogen and sulfur on growth and yield of sunflower (Helianthus annuus L.). Journal of Eco Physiology, Bikaner, v.3, n.1-2, p.59-71, 2000.

15 PÖTTKER, D.; ROMAN, E. Efeito de resíduos de culturas e do pousio de inverno sobre a resposta do milho a nitrogênio. Pesquisa Agropecuária Brasileira, Brasília, v.29, n.5, p.763-770, 1994.

16 ROSSI, R. O. Girassol. Curitiba: Tecnoagro, 1998. 333p.

17 SÁ, J. C. M. Manejo da Fertilidade do Solo no Sistema Plantio Direto. In: Soil fertility, soil biology and plant nutrition interrelationships. Lavras: Sociedade Brasileira de Ciência do Solo, 1998.

18 SÁ, J. C. M.; CERRI, C. C.; DICK, W. A.; LAL, R.; VENSKE FILHO, S. P.; PICCOLO, M. C.; FEIGL, B. E. Organic matter dynamics and carbon sequestration rates for a tillage chronosequence in a Brasilian Oxisol. Soil Science Society of America Journal, Madison, v.65, n.5, p.1486-1499, 2001.

19 SANGOI, L.; SILVA, P. R. F. da. Distribuição e acúmulo de matéria seca em duas cultivares de girassol em três épocas de semeadura. Pesquisa Agropecuária Brasileira. Brasília, v.23, n.5, p.489-502, 1988.

20 SCHNEITER, A. A.; MILLER, J. F. Description of sunflower growth stages. Crop Science. n.21, v.6, p.901-903, 1981.

21 SINCLAIR, T. R. Historical changes in harvest index and crop nitrogen accumulation. Crop Science. v.38, n.3, p.638-643, 1998.

22 STUDDERT, G. A.; ECHEVERRIA, H. E. Crop rotations and nitrogen fertilization to manage soil organic carbon dynamics. Soil Science Society of America Journal, Madison, v.64, n.4, p.1496-1503, 2000.

23 TOMÉ, J. B. Jr. Manual para interpretação de análise de solo. Guaíba: Agropecuária, 1997. 247p.

24 TORELLA, J. L.; CERIANI, J. C.; INTROCASO, R. M.; GUECAIMBURU, J.; WASINGER, E. Las labranzas, el encalado y el girasol. Agrochimica, Buenos Aires, v.45, n.1-2, p.14-23, 2001.

25 ZAGONEL, J.; MUNDSTOCK, C. M. Doses e época de aplicação de nitrogênio em cobertura em duas cultivares de girassol. Pesquisa Agropecuária Brasileira, Brasília, n.26, v.9, p.1487-1492, 1991. 